\title{
Editorial
}

\section{Towards a United Front against Weight Bias}

\author{
Carole-Anne Leblanc, BSc, PhD Candidate; Elisabeth Marquis, BSc, PhD Candidate; Marie-Pierre Gagnon-Girouard, PhD; \\ Benoit Brisson, PhD*
}

Département de Psychologie, Université du Québec à Trois-Rivières, Trois-Rivières, QC G9A 5H7, Canada

\section{*Corresponding author}

Benoit Brisson, PhD

Professeur Régulier, Département de Psychologie, Université du Québec à Trois-Rivières, Trois-Rivières, QC G9A 5H7, Canada;Tel. (8I9) 376-50II \#355 I

E-mail: benoit.brisson@uqtr.ca

\section{Article Information}

Received: September 25 ${ }^{\text {th }}, 2017$; Accepted: September 26 2 to17; Published: September $26^{\text {th }}, 2017$

\section{Cite this article}

Leblanc CA, Marquis E, Gagnon-Girouard MP, Brisson B. Towards a united front against weight bias. Soc Behav Res Pract Open J. 20I7; 3(I): el-e2. doi: I0.17/40/ SBRPOJ-3-e004

$\mathrm{O}$ besity is considered as one of the most alarming contemporary health issues. ${ }^{1}$ Paradoxically, as the prevalence of obesity increases, discrimination against individuals that are considered as overweight is also on the rise. ${ }^{2}$ Weight bias associates overweight with negative personal attributes, such as laziness, lack of intelligence and self-discipline, unsuccessfulness and unattractiveness. ${ }^{3}$ These biases lead to discrimination, which affects a wide range of the targeted individual's life dimensions, including education, work and healthcare, as well as interpersonal relationships. ${ }^{4}$ The pervasive effect of weight bias is so strong that even average-weight individuals who were formerly obese are rated less favorably by their peers in terms of mate value and personality. ${ }^{5}$

As such, weight bias has a direct impact on the psychological and physical well-being of targeted individuals. Amongst others, the above-mentioned negative associations with overweight perceptions and beliefs can lead to counterproductive behaviours for weight loss goals, such as binge eating, ${ }^{6}$ demotivation and avoidance to exercise, ${ }^{7}$ and fleeing medical help, ${ }^{4}$ especially when bias is internalized by targeted individuals themselves. ${ }^{8}$ This problem highlights the necessity to take into account weight bias in efforts to decrease overweight health issues. ${ }^{9}$

Beyond the impact on the targeted population, weight bias is also detrimental to other individuals, all across the weightspectrum. The ambient discourse about the necessity to maintain a healthy weight may reinforce efforts to distance oneself from overweight stereotypes, widening the gap between overweight and what is considered healthy or acceptable, ${ }^{10}$ and can contribute to the adoption of risky or disordered eating behaviors. ${ }^{11}$

Being deeply rooted in western individualistic values, weight bias has been suggested to be one of the last socially acceptable forms of prejudice. ${ }^{4}$ A recent study by our group com- pared weight bias with the less socially acceptable race bias against black individuals in a French Canadian sample. Results suggested that participants had less motivation to control their implicit weight biases, which may have led to greater explicit bias towards individuals considered as overweight, compared to explicit race bias towards black individuals, even though implicit bias towards the targeted populations was equivalent across weight and race biases (Marquis, Leblanc, Blais, Fiset, Gagnon-Girouard \& Brisson, in preparation). ${ }^{12}$

The widely held assumption that weight is controllable and a personal responsibility can also contribute to such discrimination. ${ }^{13,14}$ Even more problematic, these beliefs are reinforced by public health interventions that can inadvertently worsen weight bias by associating overweight with something to avoid at any costs. ${ }^{15,16}$

The assumption of controllability and personal responsibility, in conjunction with the model of thinness that feeds several industries, such as the diet industry, and which transpires through several medias and politics, can possibly explain why weight bias is particularly resistant to change and that most strategies have yet failed to show lasting effect on explicit and implicit weight bias; for example among health professionals. ${ }^{15}$ Furthermore, these social messages seem to affect individuals' body image and the tendency to compare oneself to others, both factors being associated to weight bias. ${ }^{17}$

All of the above, and the fact that weight bias affects women and men differently, ${ }^{11}$ suggests that weight bias is a complex phenomenon that is built on social messages and social acceptability, which can be internalised and expressed differently according to biological and psychological traits. Given the complex social and psychological interactions that influence the expression of weight 
bias, future research in the field would benefit from collegial multidisciplinary research that focuses on the impact of social messages that promote negative weight stereotypes, social acceptability and their interaction with psychological traits in different ethnic groups, cultures, age groups, sex and gender, for which the sociopsycho-biological interactions could potentially differ.

It will also be beneficial to incorporate new methods and tools to precisely objectify the social acceptability of weight bias and test innovative ways to reduce its expression. For example, neuroscience methods and techniques have been very useful in refining knowledge of race bias. ${ }^{18}$ Such efforts will bring further data to help guide political decisions that could help in decreasing implicit weight bias. As mentioned above, reducing social acceptability is not sufficient to prevent negative stereotypes to be internalized in the form of implicit biases. ${ }^{12}$ It will therefore be important to investigate new avenues to reduce implicit bias in order to obtain long-term effects that are not subject to motivation to control biases, which can be quite volatile.

In summary, we propose that to reduce weight bias and its negative social and personal impact, a united effort must be deployed to refine our knowledge of the complex web of factors underlying implicit and explicit weight bias within distinct sociopsycho-biological realities. This knowledge will benefit focused strategies regarding prevention of obesity and eating disorders as well as the promotion of healthy habits and that of a healthy weight-neutral body image, from political decisions to personalised interventions.

\section{CONFLICTS OF INTEREST}

The authors declare that they have no conflicts of interest.

\section{REFERENCES}

1. WHO. Controlling the global obesity epidemic. 2017. Web site. http://www.who.int/nutrition/topics/obesity/en/. Accessed September 24, 2017.

2. Andreyeva T, Puhl RM, Brownell KD. Changes in perceived weight discrimination among Americans, 1995-1996 through 2004-2006. Obesity. 2008; 16(5): 1129-1134. doi: 10.1038/ oby. 2008.35

3. Puhl RM, Heuer CA. Obesity stigma: Important considerations for public health. Am J Public Health. 2010; 100(6): 1019-1028. doi: 10.2105/АJPH.2009.159491

4. Puhl RM, Heuer CA. The stigma of obesity: A review and update. Obesity. 2009; 17(5): 941-964. doi: 10.1038/oby.2008.636

5. Carels RA, Rossi J, Solar C, Selensky JC. Changes in perceived mate value and weight bias associated with former obesity status. Stigma and Health. 2017.
6. Almeida L, Savoy S, Boxer P. The role of weight stigmatization in cumulative risk for binge eating. J Clin Psychol. 2011; 67(3): 278292. doi: $10.1002 /$ jclp.20749

7. Pearl RL, Puhl RM, Dovidio JF. Differential effects of weight bias experiences and internalization on exercise among women with overweight and obesity. J Health Psychol. 2015; 20(12): 16261632. doi: $10.1177 / 1359105313520338$

8. O’Brien KS, Latner JD, Puhl RM, et al. The relationship between weight stigma and eating behavior is explained by weight bias internalization and psychological distress. Appetite. 2016; 102: 70-76. doi: 10.1016/j.appet.2016.02.032

9. Alberga AS, Russell-Mayhew S, von Ranson KM, McLaren, L. Weight bias: A call to action. J Eat Disord. 2016; 4: 1-6. doi: 10.1186/s40337-016-0112-4

10. Rodgers RF. The role of the 'Healthy Weight' discourse in body image and eating concerns: An extension of sociocultural theory. Eating Behaviors. 2016; 22: 194-198. doi: 10.1016/j.eatbeh.2016.06.004

11. Puhl R, Suh Y. Stigma and eating and weight disorders. Curr Psychiatry Rep. 2015; 17(3): 10. doi: 10.1007/s11920-015-0552-6

12. Marquis E, Leblanc C, Blais C, Fiset D, Gagnon-Girouard M, Brisson B. The effect of social acceptability on the implicit and explicit expression of weight bias: A comparison with racism. In preparation. 2017.

13. Crandall CS. Prejudice against fat people: Ideology and selfinterest. J Pers Soc Psychol. 1994; 66(5), 882-894. doi: 10.1037/00223514.66.5.882

14. Puhl RM, Schwartz MB, Brownell KD. Impact of perceived consensus on stereotypes about obese people: A new approach for reducing bias. Health Psychology. 2005; 24(5): 517-525. doi: 10.1037/0278-6133.24.5.517

15. Alberga AS, Pickering BJ, Alix Hayden K, et al. Weight bias reduction in health professionals: A systematic review. Clin Obes. 2016; 6(3): 175-188. doi: 10.1111/cob.12147

16. Puhl R, Luedicke J, Peterson JL. Public reactions to obesityrelated health campaigns: A randomized controlled trial. Am J Prev Med. 2013; 45(1): 36-48. doi: 10.1016/j.amepre.2013.02.010

17. Leblanc CA, Gagnon-Girouard MP, Blais C, Bisson B. Weight bias among young adults: Could one's own body image issues matter the most? Submitted. 2017.

18. Amodio DM. The neuroscience of prejudice and stereotyping. Nat Rev Neurosci. 2014; 15(10): 670-682. doi: 10.1038/nrn3800 